\title{
A genome-wide association study of asthma symptoms in Latin American children
}

Gustavo N. O. Costa ${ }^{1 *}$, Frank Dudbridge ${ }^{12}$, Rosemeire L. Fiaccone ${ }^{2}$, Thiago M. da Silva ${ }^{1}$, Jackson S. Conceição ${ }^{2}$, Agostino Strina', Camila A. Figueiredo ${ }^{3}$, Wagner C. S. Magalhães ${ }^{4}$, Maira R. Rodrigues ${ }^{4}$, Mateus H. Gouveia ${ }^{4}$, Fernanda S. G. Kehdy ${ }^{4}$, Andrea R. V. R. Horimoto ${ }^{5}$, Bernardo Horta ${ }^{6}$, Esteban G. Burchard ${ }^{7}$, Maria Pino-Yanes ${ }^{7}$, Blanca Del Rio Navarro ${ }^{8}$, Isabelle Romieu ${ }^{9}$, Dana B. Hancock ${ }^{10}$, Stephanie London ${ }^{8}$, Maria Fernanda Lima-Costa ${ }^{11}$, Alexandre C. Pereira ${ }^{11}$, Eduardo Tarazona ${ }^{4}$, Laura C Rodrigues ${ }^{13}$ and Mauricio L. Barreto ${ }^{1,14}$

\begin{abstract}
Background: Asthma is a chronic disease of the airways and, despite the advances in the knowledge of associated genetic regions in recent years, their mechanisms have yet to be explored. Several genome-wide association studies have been carried out in recent years, but none of these have involved Latin American populations with a high level of miscegenation, as is seen in the Brazilian population.
\end{abstract}

Methods: 1246 children were recruited from a longitudinal cohort study in Salvador, Brazil. Asthma symptoms were identified in accordance with an International Study of Asthma and Allergies in Childhood (ISAAC) questionnaire. Following quality control, 1877526 autosomal SNPs were tested for association with childhood asthma symptoms by logistic regression using an additive genetic model. We complemented the analysis with an estimate of the phenotypic variance explained by common genetic variants. Replications were investigated in independent Mexican and US Latino samples.

Results: Two chromosomal regions reached genome-wide significance level for childhood asthma symptoms: the $14 q 11$ region flanking the DAD1 and OXA1L genes (rs1999071, MAF 0.32, OR 1.78, $95 \%$ Cl 1.45-2.18, p-value $2.83 \times 10^{-8}$ ) and 15q22 region flanking the FOXB1 gene (rs10519031, MAF 0.04, OR 3.0, $95 \%$ Cl 2.02-4.49, $p$-value $6.68 \times 10^{-8}$ and rs8029377, MAF 0.03, OR 2.49, $95 \%$ Cl 1.76-3.53, p-value $2.45 \times 10^{-7}$ ). eQTL analysis suggests that rs 1999071 regulates the expression of OXA1L gene. However, the original findings were not replicated in the Mexican or US Latino samples.

Conclusions: We conclude that the $14 \mathrm{q} 11$ and $15 \mathrm{q} 22$ regions may be associated with asthma symptoms in childhood.

Keywords: Asthma symptoms, Genome-wide association, Latin America, Children

\section{Background}

Asthma is classified as a complex and inflammatory disease of the respiratory tract with distinct phenotypes and has a major impact on mortality, morbidity and quality of life. However, the geographical area in which it occurs should be taken into account in order to reflect on its complexity. It has been occurring increasingly in Latin America and a number of authors attribute a part

\footnotetext{
* Correspondence: gustavokosta@gmail.com

${ }^{1}$ Instituto de Saúde Coletiva, Universidade Federal da Bahia, Salvador, Brazil Full list of author information is available at the end of the article
}

of this rise to the social and urban inequalities present in these countries [1].

Recent reviews suggest that a significant amount of childhood asthma could be attributed to genetic inheritance [2]. A considerable number of studies on candidate genes have been carried out in recent years, based on an immunological understanding of asthma, in an attempt to understand the genetic mechanisms of asthma, but inconsistent replication suggested that these studies mostly reported false-positive results [3]. A further important observation is that the studies on association between genetics and asthma were predominantly 
developed in populations of North American and European origin ${ }^{4}$, where the profile of disease differs from the asthma established in Latin American populations.

The use of Genome-Wide Association Studies (GWAS) as an alternative to candidate gene association analyses has become possible with the development of genomic analysis techniques. GWAS is a form of studying genetic association in which hundreds of thousands of single nucleotide polymorphisms (SNPs) are evaluated through relations with a specific phenotype, without a previous causal hypothesis [4].

The first GWAS of asthma identified various markers in the 17q21 region, with common variants that appear to contribute to a substantial proportion of asthma cases in the group of children investigated [5]. Later studies revealed that this region is important not only for asthma in children and highlighted the importance of other genes such as the chromosome 18 cluster IL1RL1/ IL18R1 in adults [6] and PDE11A in children [7], among others. In turn, GWAS in non-white populations have indicated different SNPs for asthma, such as $A D R A 1 B$, $R P P N$, and DPP10 [8].

This study differs from others as it considers an extremely admixed population, which does not correspond to the USA-Europe axis and seeks to understand the genetic basis of asthma symptoms using genome-wide techniques. The potential advantages of this approach are higher frequencies of some disease SNPs, greater extent of linkage disequilibrium due to admixture and increased effect sizes for SNPs in the presence of certain environmental risk factors, for example, changes in diet, physical activity, exposure to allergens, indoor pollutants and psychosocial factors [1].

This study aims to explore the effects of genetic markers on asthma symptoms in a population of children living in the city of Salvador, Brazil by means of a GWAS. We then assessed the heritability in this population and investigated the possible metabolic pathways associated with asthma symptoms.

\section{Results}

After quality control, 1246 children aged 5 to 12 years old were analysed. 673 of these were male and 573 female. From this total, 280 (22\%) presented asthma symptoms which were defined as cases, $55.5 \%$ male and $44.5 \%$ female. The others 966 (78 \%) without asthma symptoms was defined as controls, $53.6 \%$ male and $46.3 \%$ female.

\section{Association test}

Following a PCA adjustment for ancestry (Additional file 1: Figure S1), the genomic inflation factor $(\lambda)$ was 1.04 , indicating a low probability of false-positive associations as a result of population structure. The most strongly associated SNPs were found on chromosome 14 (region 14q11, Fig. 1), rs1999071 variant (OR:

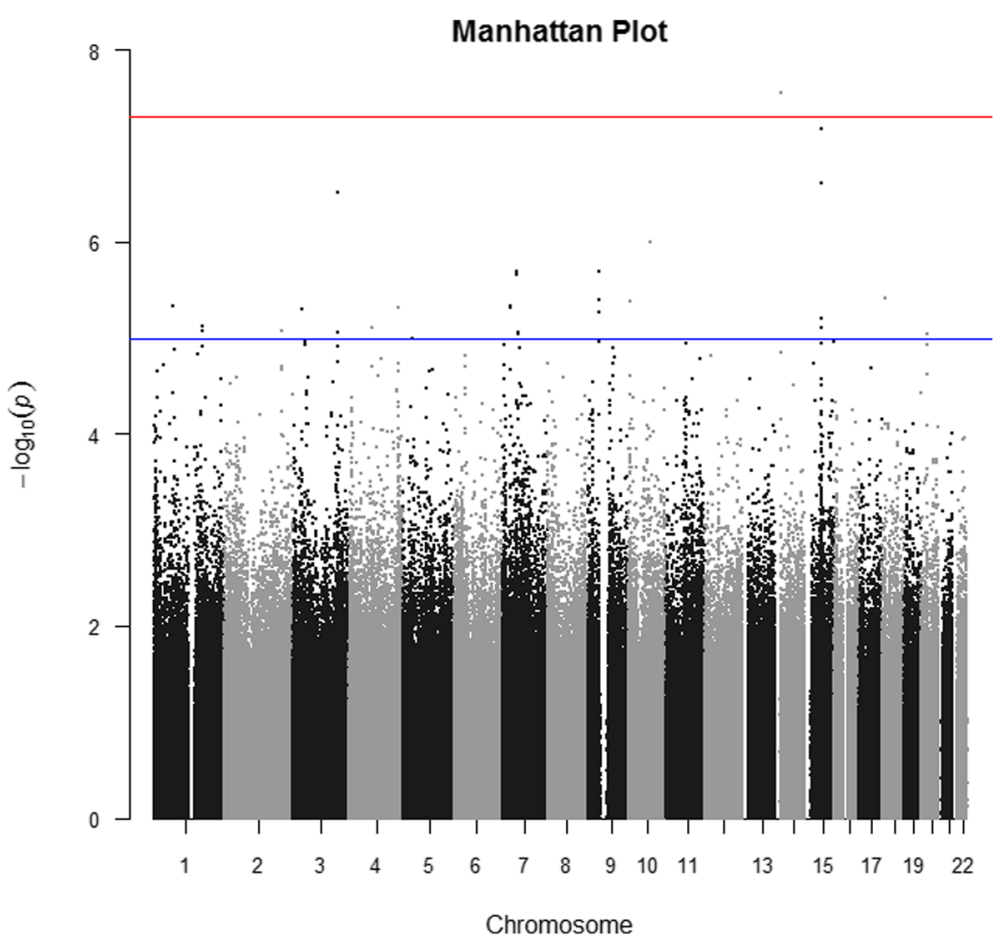

Fig. 1 Manhattan plot for asthma symptoms in children, adjusted for population structure 
1.78; $95 \%$ CI: $1.45-2.18$; $p$-value: $2.83 \times 10^{-8}$ ) in the intergenic region of $100 \mathrm{~kb}$ up-stream to the OXA1L (oxidase (cytochrome c) assembly 1-like) gene. The second most associated chromosome region was $15 \mathrm{q} 21$, specifically SNPs rs10519031 (OR: 3.0; 95 \% CI: 2.02-4.49; p-value: $6.68 \times 10^{-8}$ ) and rs8029377 (OR: 2.49; $95 \%$ CI: 1.76-3.53; $p$-value: $\left.2.45 \times 10^{-7}\right)$, both in an intergenic region. Table 1 lists the 20 most significant SNPs (for further information, see Additional file 1: Table S2). The quantilequantile plot revealed some deviations in the tail, but not systematic deviation, indicating that SNPs which are genuinely associated with asthma symptoms could be present (Fig. 2). Following imputation for chromosomes 14 and 15, we observed that the associated SNPs with greater statistical significance remained and were identified as belonging to the regions flanking the DAD1 and OXA1L genes in chromosome $14 \mathrm{q} 11$ and FOXB1 in chromosome 15q21 (Figs. 3 and 4).

We examined whether rs1999071 is associated with differential expression of DAD1 and OXA1L in chromosome 14 using the GTEx browser [9] in lung tissue and transformed fibroblast cells (Fig. 5). We found differential expression of OXA1L in lung tissue (GTEX $p$-value: 0.003).

For replication in GALA II and MCCAS, we provided a list of 75 SNPs, in which 25 were the most associated in the initial analysis, to which were added the most associated SNPs in the 14q11 and $15 \mathrm{q} 21$ regions after imputation (25 SNPs for each chromosome). In GALA II, 65 SNPs were available (Additional file 1: Table S3), but only one SNP in chromosome 10, rs10159952, was replicated (OR: 1.37; 95 \% CI: 1.07-1.76; $p$-value: 0.01). This SNP is an intronic variant in the C10orf11 gene and remained associated after combined analysis (OR combined: 1.63; $95 \%$ CI: 1.35-1.97; $p$-value combined: $4.03 \times 10^{-07}$ ). In MCCAS, the data were available on 14 SNPs overall, however no SNP had a $P$ value $<0.05$ (Additional file 1: Table S3), and the combined $p$-value of rs10159962 was $3.25 \times 10^{-06}$.

\section{The proportion of phenotypic variance explained by the genome}

It is observed in Table 2 that $70 \%$ of the total phenotypic variation (liability for asthma symptoms) was explained by the genotyped SNPs ( $p$-value: 0.001$)$. This variance dropped to $69 \%$ with the removal of the 20 most associated SNPs and to $12 \%$ in an analysis of the 20 most associated SNPs; however the standard errors on each of these values are large. In the analysis separated by chromosome, chromosomes 4, 7, 10, 13 and 15 were those which most explained asthma symptoms (Additional file 1: Figure S2).

Table 1 The 20 SNPs which are most associated with asthma, corrected by the first three principal components for ancestry

\begin{tabular}{|c|c|c|c|c|c|c|c|c|c|}
\hline Rank & Chromosome & SNP & Position (bp) & Risk Allele & MAF & Gene & Odds ratio & IC (95\%) & $p$ \\
\hline 1 & 14 & rs1999071 & 23129207 & $C$ & 0.32 & Intergenic & 1.78 & $(1.45-2.18)$ & $2.834 \times 10^{-08}$ \\
\hline 2 & 15 & rs10519031 & 60183005 & C & 0.04 & Intergenic & 3.01 & $(2.02-4.49)$ & $6.676 \times 10^{-08}$ \\
\hline 3 & 15 & rs8029377 & 60191985 & C & 0.06 & Intergenic & 2.49 & $(1.76-3.53)$ & $2.454 \times 10^{-07}$ \\
\hline 4 & 3 & rs77165709 & 159452876 & T & 0.08 & IQCJ-SCHIP1 & 2.27 & $(1.66-3.18)$ & $3.045 \times 10^{-07}$ \\
\hline 5 & 10 & rs10159952 & 77562470 & A & 0.09 & C10orf11 & 2.04 & $(1.53-2.72)$ & $1.016 \times 10^{-06}$ \\
\hline 6 & 9 & rs1329568 & 37037976 & $\mathrm{~T}$ & 0.11 & LOC100130458 & 1.93 & $(1.47-2.54)$ & $2.02 \times 10^{-06}$ \\
\hline 7 & 7 & rs1425883 & 49754984 & $\mathrm{~T}$ & 0.36 & Intergenic & 0.60 & $(0.49-0.74)$ & $2.037 \times 10^{-06}$ \\
\hline 8 & 7 & rs1543902 & 49754752 & G & 0.36 & Intergenic & 0.60 & $(0.49-0.74)$ & $2.164 \times 10^{-06}$ \\
\hline 9 & 18 & rs76227669 & 10787366 & $\mathrm{~T}$ & 0.02 & PIEZO2 & 4.06 & $(2.24-7.36)$ & $3.881 \times 10^{-06}$ \\
\hline 10 & 9 & rs4878674 & 37036329 & $\mathrm{~T}$ & 0.12 & Intergenic & 1.90 & $(1.45-2.49)$ & $4.027 \times 10^{-06}$ \\
\hline 11 & 10 & rs1244495 & 7881339 & G & 0.38 & TAF3 & 0.61 & $(0.50-0.75)$ & $4.169 \times 10^{-06}$ \\
\hline 12 & 1 & rs269330 & 68548590 & $\mathrm{~T}$ & 0.16 & GNG12-AS1 & 1.75 & $(1.38-2.22)$ & $4.669 \times 10^{-06}$ \\
\hline 13 & 7 & rs10268364 & 28708465 & C & 0.36 & CREB5 & 1.59 & $(1.30-1.94)$ & $4.671 \times 10^{-06}$ \\
\hline 14 & 7 & rs41335 & 28704468 & C & 0.49 & CREB6 & 0.64 & $(0.52-0.77)$ & $4.793 \times 10^{-06}$ \\
\hline 15 & 4 & rs72998173 & 173715118 & G & 0.14 & GALNTL6 & 1.76 & $(1.38-2.24)$ & $4.848 \times 10^{-06}$ \\
\hline 16 & 3 & rs4373023 & 34077223 & $\mathrm{~T}$ & 0.43 & Intergenic & 1.57 & $(1.29-1.91)$ & $4.977 \times 10^{-06}$ \\
\hline 17 & 9 & rs1329567 & 37038326 & A & 0.09 & LOC100130458 & 1.97 & $(1.47-2.64)$ & $5.46 \times 10^{-06}$ \\
\hline 18 & 9 & rs2381598 & 37041246 & C & 0.09 & Intergenic & 1.97 & $(1.47-2.64)$ & $5.474 \times 10^{-06}$ \\
\hline 19 & 15 & rs12901887 & 56941976 & G & 0.23 & ZNF280D & 0.56 & $(0.43-0.72)$ & $6.224 \times 10^{-06}$ \\
\hline 20 & 1 & rs79530846 & 171950308 & $\mathrm{~T}$ & 0.03 & vDNM3 & 3.08 & $(1.88-5.03)$ & $7.542 \times 10^{-06}$ \\
\hline
\end{tabular}




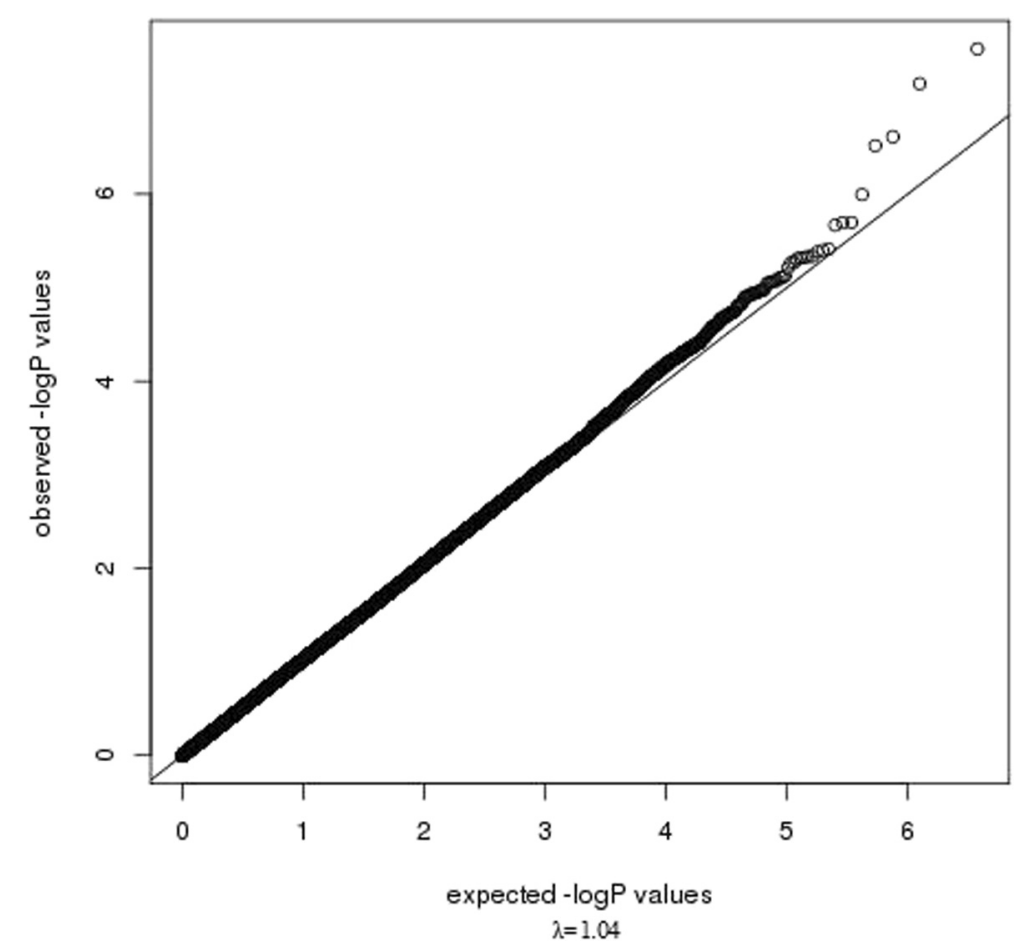

Fig. 2 QQ-plot for childhood asthma symptoms, adjusted for population structure

\section{Enrichment analysis}

This analysis is based on prior knowledge of the genes involved in known biological pathways, testing the association between them with the phenotype of interest. All of the metabolic pathways were examined, with 20 presenting empirical $p$-values of less than 0.05 and the haematopoiesis pathway which had an empirical $p$-value of less than $10^{-3}$ : (GO:0030097, p-empirical: $7.9 \times 10^{-4}$ ). However, these pathways lost statistical significance following multiple test correction (Table 3).

\section{Discussion}

We have carried out a GWA study of asthma symptoms in 1246 children in the population of Salvador, Brazil. The $14 \mathrm{q} 11$ and $15 \mathrm{q} 22$ regions were associated with asthma symptoms.

The $14 q 11$ region has already been reported in different GWA studies associated with dental development [10], obesity [11], narcolepsy [12] and cancer [13]. However, this association in asthma studies had not yet been reported. We analysed the LD between rs1999071 and each of the SNPs on 14q11 region presented in those publications, but none of them were in $\operatorname{LD}\left(\mathrm{r}^{2} \geq 0.80\right)$ with rs1999071 in our population. If rs1999071 is involved in asthma pathogenesis, then it is unlikely to represent a shared aetiology with the conditions above.

Studies on candidate genes in the $14 \mathrm{q} 11$ region found association with SNPs in genes involved in the modulation of inflammatory and immunological responses. The LTB4 (leukotriene beta 4 receptor) gene was associated to asthma [14] and TRA (T cell alpha receptor) associated with a skin prick test (SPT) in a linkage study in a group of asthmatic families [15]. Furthermore, based on described biological functions, it is reasonable to suppose that genes which are potentially associated with asthma symptoms may be located in this region, with the example of SLC7A7, MMP14 and DAD1. The SLC7A7 gene is involved in the macrophage differentiation process [16] and its involvement in asthma pathogenesis has been described [17]. MMP14 is involved with remodelling the extracellular matrix [18] and, specifically, the remodelling of the airway epithelium [19]. $D A D 1$ is active in the apoptosis regulation process [20] and its failure in this process may lead to increased lymphocytes in asthma patients [21]. The variant which was most associated in this study, rs1999071, is located in the region flanking the OXA1L gene that encodes a component of the evolutionarily conserved Oxa1/Alb3/YidC protein family, which is involved in the biogenesis of membrane proteins of mitochondria, chloroplasts and bacteria [22]. Although asthma is not considered a mitochondrial syndrome, there is a considerable overlap between asthma pathophysiology and mitochondrial biology in aspects of apoptosis, oxidative stress and homeostasis of calcium ions [23]. Alterations to oxidative stress may lead to developing asthma by activating pro-inflammatory pathways [24]. Alteration of the $\mathrm{Ca}^{++}$ 

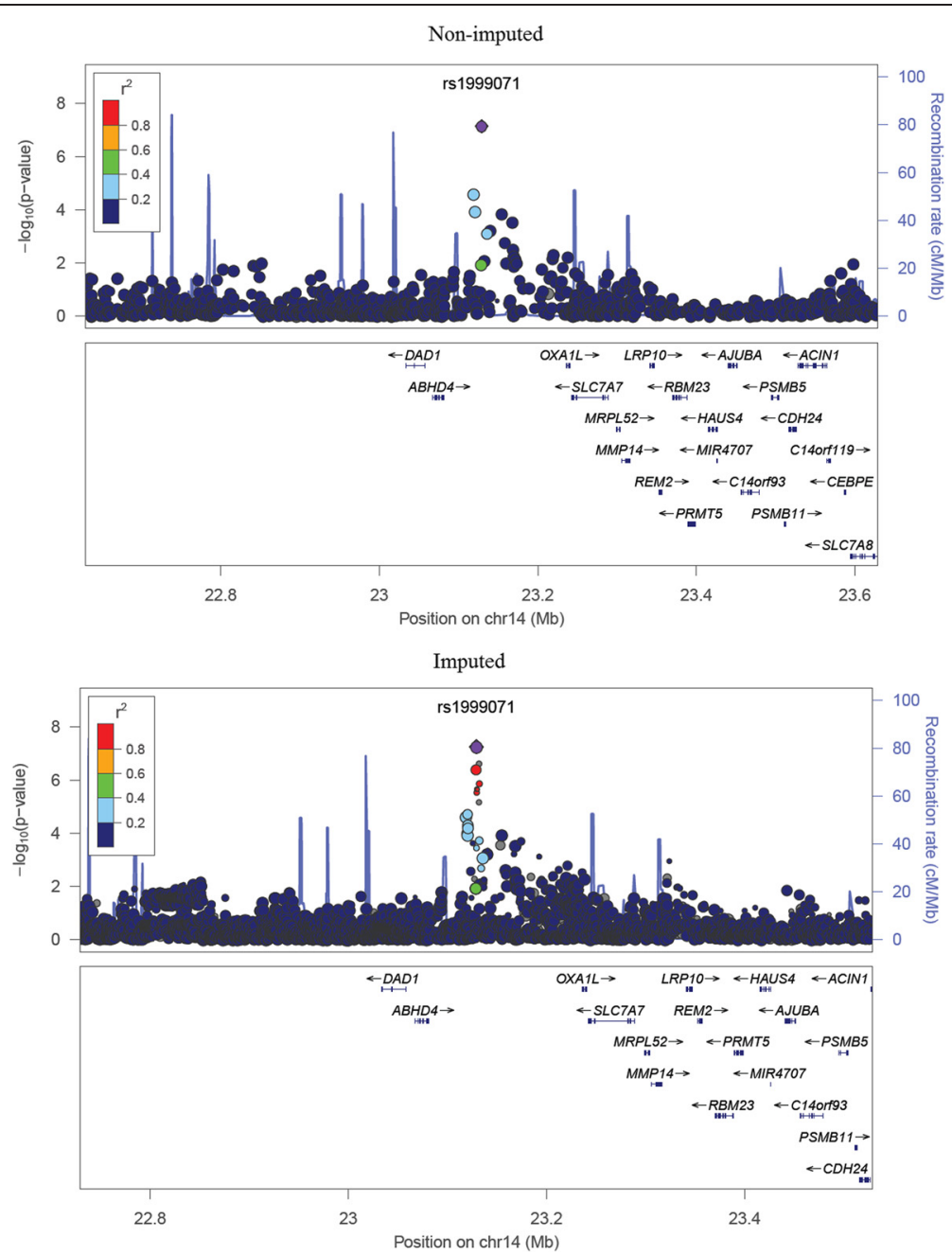

Fig. 3 Regional plot of chromosome 14, which is the region most associated with childhood asthma symptoms

homeostasis in the bronchial smooth muscle cells increases mitochondrial biogenesis, cellular proliferation and, consequently, remodelling of the airways in asthmatic patients [25].

The second most associated region in this study was 15q21, the rs10519031 flanks the FOXB1 gene which belongs to the family of FOX (forkhead box) transcription factors, with more than 40 members expressed in mammals. Mutations in this group of genes have important effects on human diseases [26]. However, the FOXB1 protein has only been described as being involved in regulating embryonic development [27] until this time.

The 15q21 has already been described in GWA of asthma, with the most associated genes being RORA, SMAD3 and SCG3 [28]. RORA is a transcription factor which belongs to the nuclear hormone receptor (NR1) superfamily and links as monomers to specific hormonal response elements in the DNA [29]. It may increase or restrain the transcription of target genes [30] and is differentially expressed during development of the human lung. SMAD3 (SMAD protein family member 3 ) is a (later) downstream transcription factor of TGF $\beta$ and is important for metabolic pathways of regulatory $\mathrm{T}$ cells and TH17 [31] cells. It is related to the metabolic pathway of regulatory $\mathrm{T}$ cells which forms part of the common [32] process of negative regulation of TH1 and TH2 [33]. SCG3 (secretogranin 3) encodes a protein member of the neuroendocrine secretory protein family, chromogranin/ secretogranin, which are ubiquitous protein regulators of protein secretion [34]. However, there has been little research on its functions.

An important disagreement between our study and previous GWAs findings was the absence of association in the 17q21 region [5] with asthma symptoms. However, the power of our study was limited by the sample size of 280 cases and 966 controls, and we may simply have been underpowered to detect previously known SNPs. Our limited sample size probably accounts also for the high effect 

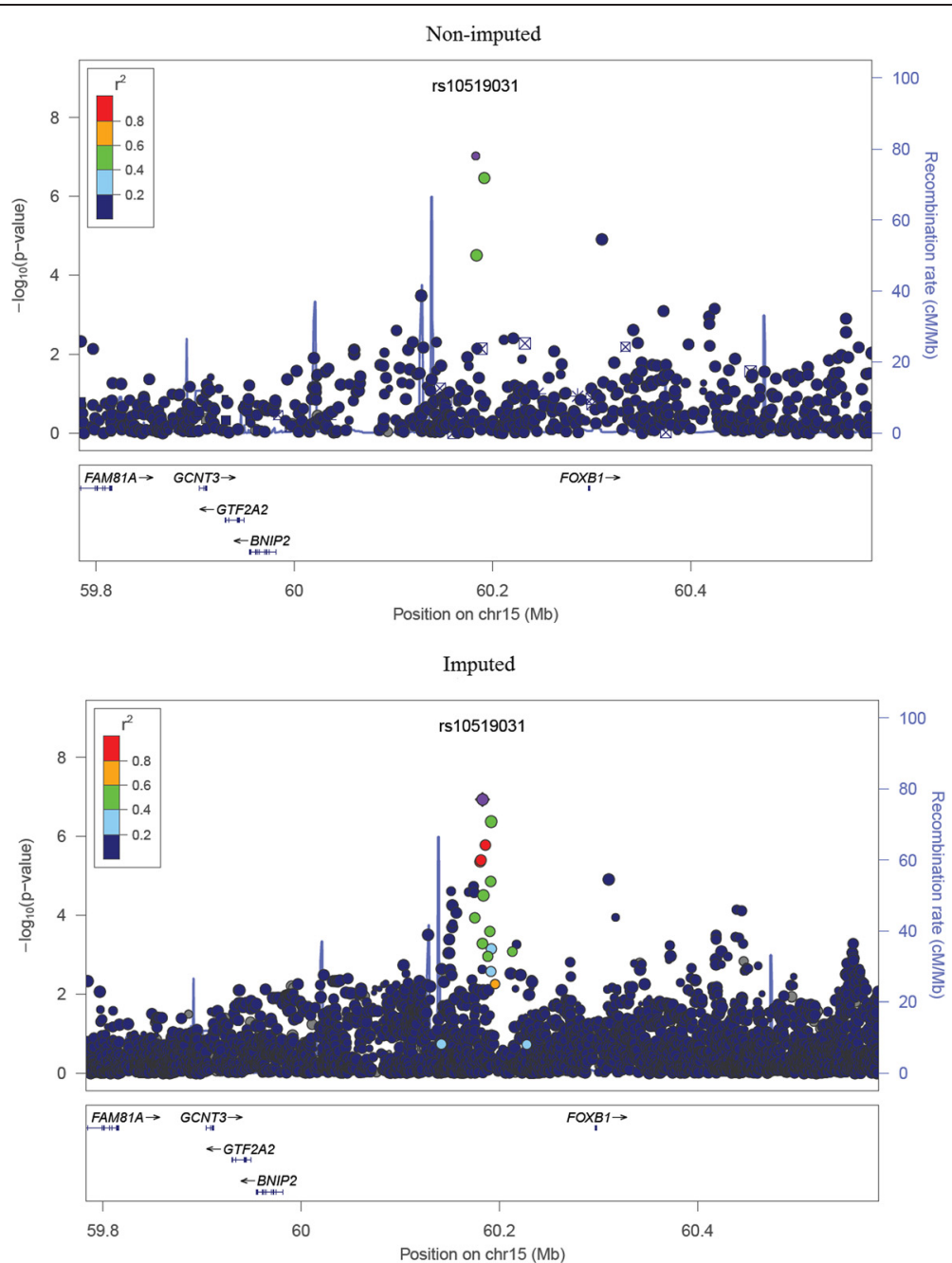

Fig. 4 Regional plot of chromosome 15, which is the second region most associated with childhood asthma symptoms

sizes of the associated SNPs in our study, ranging from 1.78 to 3.0; while our observed associations were genomewide significant, they were probably biased upwards by the "winner's curse" effect [35] . Independent replication is needed to confirm these associations and accurately estimate their effect sizes. We did not achieve compelling replication in Mexican and Latino United States cohorts, but this could have been affected by differences in phenotype definition, sample ancestry, available SNPs and sample size.

For the majority of complex diseases, the associated SNPs from genome-wide association studies (GWAs) only explain a small fraction of heritability. The estimate of the variance explained in liability to asthma symptoms was $70 \%$ in this article, which is a high but also consistent with previous findings in family studies [36] and in cohort studies [37]. These results reinforce the idea that asthma is a complex disease with polygenic inheritance in which individually different genes and their polymorphisms contribute very little to the outcome, but there is a major effect when they are analysed together. Analysis with GCTA explained a substantial proportion of the "missing heritability" and provided evidence that the additive genetic influence of various common SNPs is a powerful determinant of childhood asthma.

It is important to understand that genome-wide studies have analytical limitations, such as not detecting rare variants. Therefore, other complementary approaches are needed such as resequencing, gene expression analysis and replication in other populations. The main limitation of this study is related to power, as the number of cases was relatively small in this prospective cohort, and does not, for example, allow us to differentiate atopic from non-atopic asthma. The sample used was considered adequate for classic epidemiological studies but genome-wide or enrichment studies require a larger sample population 


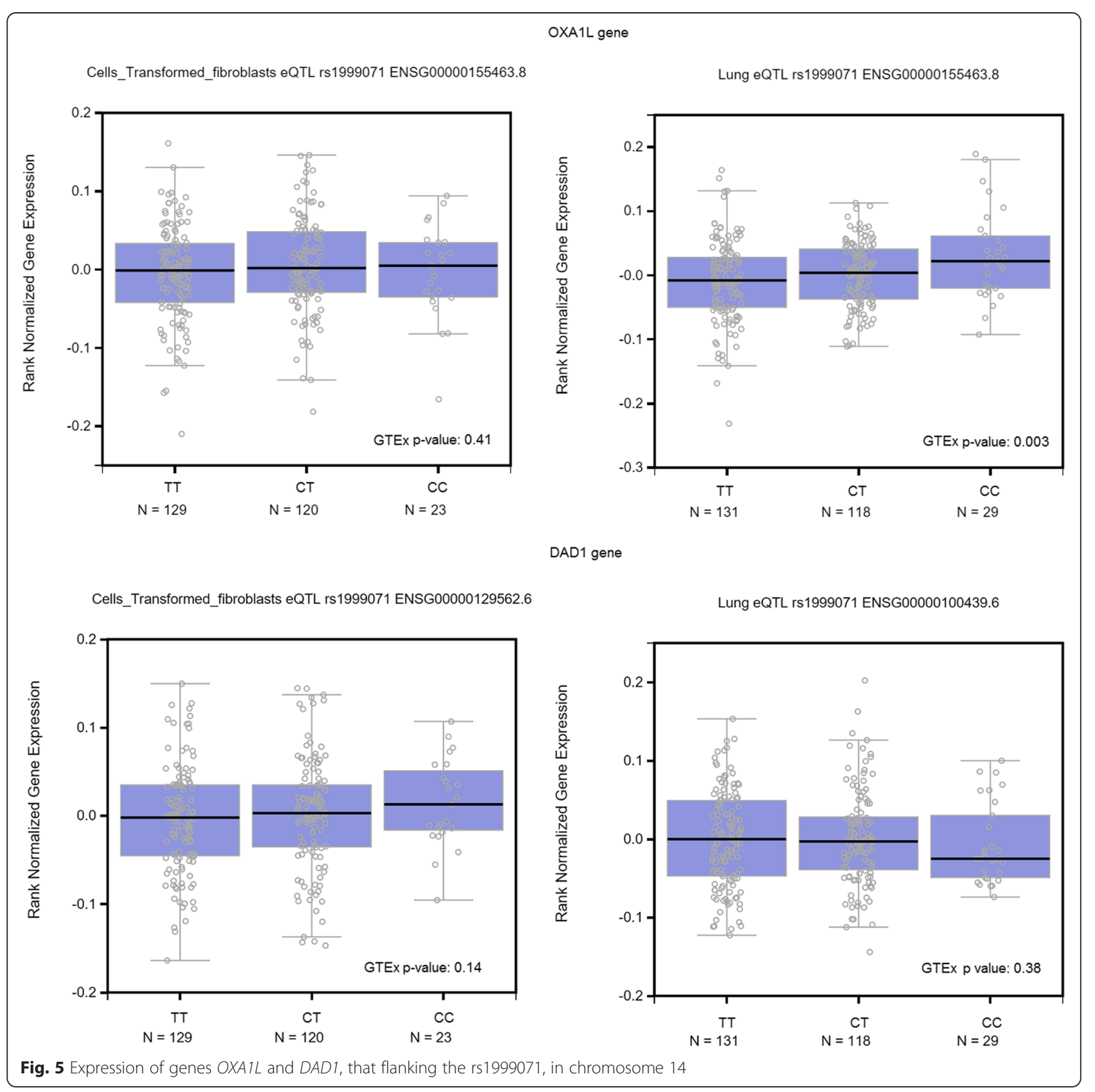

Fig. 5 Expression of genes OXA1L and DAD1, that flanking the rs1999071, in chromosome 14

Table 2 Genomic variance analysis of asthma symptoms ${ }^{a}$

\begin{tabular}{lccc}
\hline & $V_{g} N_{p}$ & Standard error & $P$-value \\
\hline All of the SNPs & 0.70 & 0.25 & 0.001 \\
All of the SNPs, except for the 20 & 0.69 & 0.25 & 0.001 \\
most associated with the outcome. & & & \\
$\begin{array}{l}\text { Only the 20 SNPs most associated } \\
\text { to the GWA study }\end{array}$ & 0.12 & 0.04 & 0 \\
\hline
\end{tabular}

${ }^{a}$ Corrected by sex and the first three principal components of ancestry than in classical analyses and it is possible that no metabolic pathway associated to asthma symptoms was found as a result.

\section{Conclusions}

Finally, it is concluded that the $14 \mathrm{q} 11$ and $15 \mathrm{q} 21$ regions may be associated with asthma symptoms in childhood in the population studied. In addition, eQTL analysis suggests that rs1999071 at 14q21, associated with asthma in this study, regulates the expression of OXA1L in lung tissue. But these regions explain less than $12 \%$ of variation 
Table 3 Metabolic pathways associated with asthma symptoms suggested by enrichment analysis

\begin{tabular}{|c|c|c|c|c|c|}
\hline Metabolic pathway & $\begin{array}{l}\text { Total number of } \\
\text { genes in the interval }\end{array}$ & $\begin{array}{l}\mathrm{N}^{\circ} \text { of associated } \\
\text { genes in the interval }\end{array}$ & Genes & p-empirical & $p$-corrected \\
\hline GO:0030097: haematopoiesis & 52 & 7 & $\begin{array}{l}\text { CD164 (chr6), KIRREL3 (chr11), } \\
\text { BRCA2 (chr13), RPA1 (chr17), } \\
\text { BCL11A (chr2), PKNOX1 (chr21), } \\
\text { IKZF1 (chr7). }\end{array}$ & $7.90 \times 10^{-04}$ & 0.76 \\
\hline $\begin{array}{l}\text { GO:0070935: 3'-UTR-mediated } \\
\text { mRNA stabilization }\end{array}$ & 3 & 2 & TARDBP (chr1), ELAVL1 (chr19). & $1.39 \times 10^{-03}$ & 0.94 \\
\hline GO:001961: flagellum & 1 & 4 & $\begin{array}{l}\text { CATSPERB (chr11), SPAG16 (chr2), } \\
\text { SPAG17 (chr1), CATSPER1 (chr14). }\end{array}$ & $1.39 \times 10^{-03}$ & 0.94 \\
\hline $\begin{array}{l}\text { GO:0043922: negative } \\
\text { regulation by host of viral } \\
\text { transcription }\end{array}$ & 4 & 2 & POU2F3 (chr11),TARDBP (chr1). & $1.79 \times 10^{-03}$ & 0.94 \\
\hline $\begin{array}{l}\text { GO:000369: DNA clamp loader } \\
\text { activity }\end{array}$ & 5 & 2 & RFC2 (chr7), RFC5 (chr12). & $4.19 \times 10^{-03}$ & 0.99 \\
\hline $\begin{array}{l}\text { GO:0030212: hyaluronan } \\
\text { metabolic process }\end{array}$ & 6 & 2 & ITIH5 (chr10), ITIH2 (chr10). & $4.19 \times 10^{-03}$ & 0.99 \\
\hline $\begin{array}{l}\text { GO:0050291: sphingosine } \\
\text { N-acyltransferase activity }\end{array}$ & 5 & 2 & LASS4 (chr19), LASS3 (chr15). & $4.59 \times 10^{-03}$ & 0.99 \\
\hline $\begin{array}{l}\text { GO:0005663: DNA replication } \\
\text { factor C complex }\end{array}$ & 6 & 2 & RFC2 (chr7), RFC5 (chr12). & $5.19 \times 10^{-03}$ & 0.99 \\
\hline $\begin{array}{l}\text { GO:004649: } \\
\text { S-adenosylhomocysteine } \\
\text { metabolic process }\end{array}$ & 6 & 2 & TPMT (chr6), DNMT3A (chr2). & $5.19 \times 10^{-03}$ & 0.99 \\
\hline $\begin{array}{l}\text { GO:0006297: nucleotide-excision } \\
\text { repair, DNA gap filling }\end{array}$ & 17 & 3 & $\begin{array}{l}\text { RPA1 (chr17), RFC5 (chr12), RFC2 } \\
\text { (chr7). }\end{array}$ & $5.79 \times 10^{-03}$ & 1 \\
\hline
\end{tabular}

in liability to this phenotype. A total of $70 \%$ of variation in liability may be explained by common genetic variants, confirming the polygenic nature of asthma.

\section{Methods}

\section{Study design and characteristics of the population}

The data analysed here on asthma and genetic markers were collected in 2 005, as part of the Social Changes, Asthma and Allergy in Latin America (SCAALA) project. The SCAALA composes the EPIGEN-Brazil initiative, it is based on three well-defined ongoing population-based cohorts from Brazil's regions [38]. The design of the original cohort and data collection for asthma are described in detail elsewhere [39]. The sample in this analysis comprises 1307 children, between 5 and 12 years old, who are resident in the city of Salvador, State of Bahia, Brazil. The city has more than 2.6 million inhabitants and $80 \%$ of the population declare themselves as black or of mixed race [40].

\section{Data collection}

A questionnaire based on the second phase of the ISAAC [41] study was used, with questions on asthma symptoms which had been translated into Portuguese and applied by appropriately trained researchers during home visits. The interviews were carried out with the children's mother, father or caregiver, provided that the person providing the information knew how to describe the possible presence of signs and symptoms compatible with asthma. Written informed consent was obtained from the legal guardian of each subject. The project was approved by the ethics committees at the Federal University of Bahia (register 003-05/CEP-ISC) and National Council for Ethics in Research (CONEP, resolution number 15 895/2011).

\section{Definition of asthma symptoms}

The children were classified as asthmatic when the parents or caregiver reported wheezing in the 12 months prior to applying the questionnaire associated with any one of the following situations: diagnosis of asthma by a doctor at any time in their lives, wheezing with exercise in the last 12 months, four or more episodes of wheezing in the 12 months or waking up at night due to wheezing episodes in the last 12 months. This definition is more specific than using only wheezing in the last 12 months, more commonly reported by studies using the ISAAC questionnaire. All the other children not fulfilling these criteria were classified as non-asthmatic.

\section{Genotyping and quality control}

The genotyped SNPs were carried out with an Illumina HumanOmni2.5-8v1 Kit BeadChip (Illumina, San Diego, CA) commercial panel with 2284818 SNPs. One individual was excluded from the analysis due to 
inconsistency between the sex registered and the genetic sex, based on X chromosome SNPs. Sixty-one individuals were removed from the sample due to the relationship determined by kinship coefficients for each possible pair of individuals. This method is implemented in the REAP software (Relatedness Estimation in Admixed Populations) [42]. We considered a pair of individuals as related if the estimated kinship coefficient between them was $\geq 0.1$. This cut-off includes second- degree relatives such as a person's uncle/aunt, nephew/niece, grandparent/ grandchild or half- sibling, and any closer pair of relatives.

Quality control was carried out in stages (Additional file 1: Table S1): a genotyping call rate of less than 0.98; deviance in the Hardy-Weinberg equilibrium, with a $p$-value of less than $10^{-4}$ and Minor Allele Frequency $(M A F)$ of less than $1 \%$ [43].

\section{Replication studies}

Genes-environments \& Admixture in Latino Americans study (GALA II)

The Genes-environments \& Admixture in Latino Americans (GALA II) study is an ongoing multicenter case-control study of asthma in Latino children and adolescents, organized from the coordinating center based at the University of California, San Francisco. It is comprised of 3774 participants (1 893 asthma cases and 1881 controls). GALA II recruited Latinos from urban regions in the mainland United States (Chicago, IL; Bronx, NY; Houston, TX; San Francisco Bay Area, CA) and Puerto Rico, using a combination of community and clinic-based recruitment. Subjects were eligible if they were $8-21$ years of age, self-identified all four grandparents as Latino, and had $<10$ pack-years of smoking history. Asthma was defined based on physician diagnosis and report of symptoms and medication use within the last two years prior to the recruitment [44].

\section{Mexico City Childhood Asthma Study (MCCAS)}

This is a case-parent trio design where the population from Mexico City Childhood Asthma Study (MCCAS) has been previously described [45]. Genome wide association data were available on 498 children between the ages of 5-17 with asthma and their parents. Subjects were recruited between June 1998 and November 2003 from a paediatric allergy specialty clinic at a public hospital in central Mexico City. The childhood asthma was diagnosed by allergists at the referral clinic, according to the guidelines of the British Thoracic Society and Scottish Intercollegiate Guidelines Network.

\section{Statistical analysis \\ Genome-Wide Association}

Logistic regression was used to examine the association with asthma symptoms with an additive genetic model.
Conventionally, an association is considered suggestive when the $p$-value is between $10^{-6}$ and $5 \times 10^{-8}$ and genome-wide significantly when the $p$-value is less than $5 \times 10^{-8}$. Principal Component Analysis was carried out and its first three components were used as covariates to control confounding by population structure. In addition the genomic inflation factor $(\lambda)$ was calculated, in order to visualise and avoid inflated test statistics in the results [46]. Replication of the original finding was defined as a $p$-value of less than 0.05 with an effect in the same direction as in the GWAS. Fixed effects meta-analysis of the SCAALA and GALA II studies was performed by the GWAMA software [47]. Only $p$-values were available from MCCAS so Fisher's combined $p$-values were calculated for the meta-analysis of SCAALA, GALA II and MCCAS.

\section{SNP imputation}

The genotypes were imputed, only in regions of interest, using the IMPUTE2 package [48] on the public panel from 1000 Genomes Project Phase I data "version 3" (ALL.integrated_phase1_SHAPEIT_16-06-14.nomono.in tegrated_phase1_v3.20101123.snps_indels_svs.genotypes. nomono.haplotypes.gz) [49], which contained 1092 individuals of various ethnicities. Quality control was carried out once more following imputation and the SNPs which presented a MAF lower than $1 \%$, a deviance in the Hardy-Weinberg equilibrium $\left(p<10^{-4}\right)$ or had a genotyping call rate of under $95 \%$ were excluded.

\section{Heritability estimate}

The proportion of variance in liability for all of the SNPs was estimated as $\left(\mathrm{V}_{\mathrm{g}} / \mathrm{V}_{\mathrm{p}}\right)$ in which $\mathrm{V}_{\mathrm{g}}$ is the variance component attributable to genetic variation in the genotyped SNPs and $V_{p}$ is the total phenotypic variance observed. The GCTA software package was used, which uses genetic variant data to estimate additive genetic relationships (correlations) between distantly related individuals. The method treats the total effect of all of the SNPs as a random effect in a Mixed Linear Model (MLM) [50]. The variance of this random effect is an estimate of $V_{\mathrm{g}}$. This analysis was adjusted for sex and first three principal components.

\section{Enrichment analysis based on a defined set of genes}

An aggregation analysis was carried out, based on linkage disequilibrium in order to identify a list of genic regions associated to the outcome (parameters for PLINK = clump-p1 = 0.005; clump-p2 = 0.05; clump-r2 = 0.5 ; clump-kb $=250$ ). Regions $20 \mathrm{~kb}$ up/downstream from the initial and final transcription sites for 17529 genes in the autosomal chromosomes were then defined, according to the GRCh37/hg19 public database of catalogued genes. We performed enrichment analysis using 
the INRICH [51] program, comprising two stages. The number of times that the genomic intervals, identified a priori, including a set of predetermined genes is counted in the first stage. A second stage was carried out to correct the false-positive rate, using a permutation procedure based on 1000 repetitions in order to obtain the empirical $p$-value, representing the proportion of times that this genomic interval includes a specific gene.

\section{Additional file}

Additional file 1: Figure S1. Analysis of the principal components in the SCAALA population with all of the SNPs in order to deduce population structure. Table S2. The 100 SNPs that are most associated with childhood asthma symptoms. Table S3. Combined analysis. Figure S2. Phenotypic variance explained for each chromosome. Table S1. Quality Control steps for SNPs. (DOCX $125 \mathrm{~kb})$

\section{Abbreviations}

GWAS: Genome-Wide Association Studies; SNPs: Single Nucleotide Polymorphisms; MAF: Minor allele frequency; OR: Odds Ratio; 95 \%Cl: 95 \% Confidence Interval; SPT: Skin Prick Test; PCA: Principal Component Analysis; GTEx: Genotype-Tissue Expression; GO: Gene Ontology; GCTA: Genome-wide Complex Trait Analysis; SCAALA: Social Changes, Asthma and Allergy in Latin America; ISAAC: International Study of Asthma and Allergies in Childhood; GALA II: Genes-environments \& Admixture in Latino Americans;

MCCAS: Mexico City Childhood Asthma Study.

\section{Competing interests}

The authors have declared that no competing interests exist.

\section{Authors' contributions}

GNOC, MLB, LCR, MFLC, ACP, ET and BH conceived and designed the study. GNOC wrote the first version of the manuscript. GNOC, FD, RLF, TMS, AS, CAF and JSC participated in statistics analysis. WCSM, MRR, MHG, FSGK and ARVRH participated in the data management and imputation. EGB and MPY contributed with the replication analysis in GALA II study. BDRN, IR, DBH and SL contributed with the replication analysis in MCCA study. All the authors contributed to interpretation of data, revising the manuscript critically for important intellectual content and approved the final version.

\section{Acknowledgments}

This work was supported by the Department of Science and Technology (DECIT, Ministry of Health), National Fund for Scientific and Technological Development (FNDCT, Ministry of Science and Technology), Funding of Studies and Projects (FINEP, Ministry of Science and Technology, Brazil), the Brazilian National Research Council (CNPq) and the Wellcome Trust UK, Ref 072405/Z/03/Z.

E.G.B. was funded by grants from National Institutes of Health (HL088133, HL078885, HL004464, HL104608, HL117004, ES015794 and MD006902) and by the American Asthma Foundation, the Sandler Foundation and the RWJF Amos Medical Faculty Development Award.

Supported in part by the Intramural Research Program of the NIH, National Institute of Environmental Health Sciences, USA.

\footnotetext{
Author details

${ }^{1}$ Instituto de Saúde Coletiva, Universidade Federal da Bahia, Salvador, Brazil. ${ }^{2}$ Instituto de Matemática, Universidade Federal da Bahia, Salvador, Brazil. ${ }^{3}$ Instituto de Ciências da Saúde, Universidade Federal da Bahia, Salvador, Brazil. ${ }^{4}$ Instituto de Ciências Biológicas, Universidade Federal de Minas Gerais, Belo Horizonte, Brazil. ${ }^{5}$ Instituto do Coração, Universidade de São Paulo, São Paulo, Brazil. ${ }^{6}$ Programa de Pós Graduação em Epidemiologia, Universidade Federal de Pelotas, Pelotas, Brazil. 'Department of Medicine, University of California, San Francisco, USA. ${ }^{8}$ Department of Health and Human Services, Epidemiology Branch, National Institute of Environmental Health Sciences, National Institutes of Health, Research Triangle Park, North Carolina, USA. ${ }^{9}$ Instituto Nacional de Salud Publica, Cuernavaca, Mexico. ${ }^{10}$ Behavioral and
}

Urban Health Program, Research Triangle Institute (RTI) International, Research Triangle Park, North Carolina, USA. ${ }^{11}$ Instituto de Pesquisas Rene Rachou, Fundação Oswaldo Cruz, Belo Horizonte, Brazil. ${ }^{12}$ Department of Non-communicable Disease Epidemiology, London School of Hygiene and Tropical Medicine, London, UK. ${ }^{13}$ Department of Infectious Disease Epidemiology, London School of Hygiene and Tropical Medicine, London, UK. ${ }^{14}$ Centro de Pesquisa Gonçalo Muniz, Fundação Osvaldo Cruz, Salvador, Brazil.

Received: 20 August 2015 Accepted: 17 November 2015

Published online: 03 December 2015

\section{References}

1. Cooper PJ, Rodrigues LC, Cruz AA, Barreto ML. Asthma in Latin America: a public heath challenge and research opportunity. Allergy. 2009; 64(1):5-17.

2. Thomsen SF, van der Sluis S, Kyvik KO, Skytthe A, Backer V. Estimates of asthma heritability in a large twin sample. Clin Exp Allergy. 2010;40(7):1054-61.

3. Kabesch M. Novel asthma-associated genes from genome-wide association studies: what is their significance? Chest. 2010;137(4):909-15.

4. Weiss ST, Silverman EK. Pro: Genome-Wide Association Studies (GWAS) in Asthma. Am J Respir Crit Care Med. 2011;184(6):631-3.

5. Moffatt MF, Kabesch M, Liang L, Dixon AL, Strachan D, Heath S, et al. Genetic variants regulating ORMDL3 expression contribute to the risk of childhood asthma. Nature. 2007:448(7152):470-3.

6. Wan YI, Shrine NR, Soler Artigas M, Wain LV, Blakey JD, Moffatt MF, et al. Genome-wide association study to identify genetic determinants of severe asthma. Thorax. 2012;67(9):762-8.

7. DeWan AT, Triche EW, Xu XM, Hsu LI, Zhao C, Belanger K, et al. PDE11A associations with asthma: Results of a genome-wide association scan. J Allergy Clin Immunol. 2010;126(4):871-U321.

8. Mathias RA, Grant AV, Rafaels N, Hand T, Gao L, Vergara C, et al. A genome-wide association study on African-ancestry populations for asthma. J Allergy Clin Immunol. 2010;125(2):336-46.

9. Consortium GT. Human genomics. The Genotype-Tissue Expression (GTEx) pilot analysis: multitissue gene regulation in humans. Science. 2015; 348(6235):648-60.

10. Fatemifar G, Hoggart CJ, Paternoster L, Kemp JP, Prokopenko I, Horikoshi M, et al. Genome-wide association study of primary tooth eruption identifies pleiotropic loci associated with height and craniofacial distances. Hum Mol Gen. 2013;22(18):3807-17.

11. Comuzzie AG, Cole SA, Laston SL, Voruganti VS, Haack K, Gibbs RA, et al. Novel genetic loci identified for the pathophysiology of childhood obesity in the Hispanic population. PloS one. 2012;7(12):e51954.

12. Hallmayer J, Faraco J, Lin L, Hesselson S, Winkelmann J, Kawashima M, et al. Narcolepsy is strongly associated with the T-cell receptor alpha locus. Nat Genet. 2009;41(6):708-11.

13. Papaemmanuil E, Hosking FJ, Vijayakrishnan J, Price A, Olver B, Sheridan E, et al. Loci on 7p12.2, 10q21.2 and 14q11.2 are associated with risk of childhood acute lymphoblastic leukemia. Nat Genet. 2009;41(9):1006-10.

14. Tulah AS, Beghe B, Barton SJ, Holloway JW, Sayers I. Leukotriene B4 receptor locus gene characterisation and association studies in asthma. BMC Med Genet. 2012;13:110.

15. Mansur AH, Bishop DT, Markham AF, Morton NE, Holgate ST, Morrison JF. Suggestive evidence for genetic linkage between lgE phenotypes and chromosome 14q markers. Am J Respir Crit Care Med. 1999;159(6):1796-802.

16. Barilli A, Rotoli BM, Visigalli R, Bussolati O, Gazzola GC, Dall'Asta V. Arginine transport in human monocytic leukemia THP-1 cells during macrophage differentiation. J Leukoc Biol. 2011;90(2):293-303.

17. Shirey KA, Pletneva LM, Puche AC, Keegan AD, Prince GA, Blanco JC, et al. Control of RSV-induced lung injury by alternatively activated macrophages is IL-4R alpha-, TLR4-, and IFN-beta-dependent. Mucosal Immunol. 2010;3(3): 291-300.

18. Niarakis A, Giannopoulou E, Ravazoula P, Panagiotopoulos E, Zarkadis IK, Aletras AJ. Detection of a latent soluble form of membrane type 1 matrix metalloprotease bound with tissue inhibitor of matrix metalloproteinases-2 in periprosthetic tissues and fluids from loose arthroplasty endoprostheses. FEBS J. 2013;280(24):6541-55.

19. Roberts ME, Magowan L, Hall IP, Johnson SR. Discoidin domain receptor 1 regulates bronchial epithelial repair and matrix metalloproteinase production. Eur Respir J. 2011;37(6):1482-93. 
20. Kelleher DJ, Gilmore R. DAD1, the defender against apoptotic cell death, is a subunit of the mammalian oligosaccharyltransferase. Proc Natl Acad Sci U S A. 1997;94(10):4994-9.

21. Persson C. Airway, apoptosis, and asthma. Clin Exp Allergy. 2013;43(9):1083-5.

22. Stiburek L, Fornuskova D, Wenchich L, Pejznochova M, Hansikova H, Zeman J. Knockdown of human Oxa1l impairs the biogenesis of F1Fo-ATP synthase and NADH:ubiquinone oxidoreductase. J Mol Biol. 2007;374(2):506-16.

23. Mabalirajan U, Ghosh B. Mitochondrial dysfunction in metabolic syndrome and asthma. J Allergy (Cairo). 2013;2013:340476.

24. Nandedkar SD, Weihrauch D, Xu H, Shi Y, Feroah T, Hutchins W, et al. D-4F, an apoA-1 mimetic, decreases airway hyperresponsiveness, inflammation, and oxidative stress in a murine model of asthma. J Lipid Res. 2011;52(3): 499-508.

25. Trian T, Benard G, Begueret H, Rossignol R, Girodet PO, Ghosh D, et al. Bronchial smooth muscle remodeling involves calcium-dependent enhanced mitochondrial biogenesis in asthma. J Exp Med. 2007;204(13): 3173-81.

26. Hannenhalli $\mathrm{S}$, Kaestner $\mathrm{KH}$. The evolution of Fox genes and their role in development and disease. Nat Rev Genet. 2009;10(4):233-40.

27. Zhao T, Szabo N, Ma J, Luo L, Zhou X, Alvarez-Bolado G. Genetic mapping of Foxb1-cell lineage shows migration from caudal diencephalon to telencephalon and lateral hypothalamus. Eur J Neurosci. 2008;28(10):1941-55.

28. Moffatt MF, Gut IG, Demenais F, Strachan DP, Bouzigon E, Heath S, et al. A Large-Scale, Consortium-Based Genomewide Association Study of Asthma. N Engl J Med. 2010:363(13):1211-21.

29. Jetten AM. Retinoid-related orphan receptors (RORs): critical roles in development, immunity, circadian rhythm, and cellular metabolism. Nucl Recept Signal. 2009;7:e003

30. Sato TK, Panda S, Miraglia LJ, Reyes TM, Rudic RD, McNamara P, et al. A functional genomics strategy reveals Rora as a component of the mammalian circadian clock. Neuron. 2004;43(4):527-37.

31. Martinez GJ, Zhang Z, Chung Y, Reynolds JM, Lin X, Jetten AM, et al. Smad3 differentially regulates the induction of regulatory and inflammatory $T$ cell differentiation. J Biol Chem. 2009:284(51):35283-6.

32. Melen E, Kho AT, Sharma S, Gaedigk R, Leeder JS, Mariani TJ, et al. Expression analysis of asthma candidate genes during human and murine lung development. Respir Res. 2011;12:86.

33. Li X, Ampleford EJ, Howard TD, Moore WC, Torgerson DG, Li H, et al. Genome-wide association studies of asthma indicate opposite immunopathogenesis direction from autoimmune diseases. J Allergy Clin Immunol. 2012;130(4):861-8. e867.

34. Bartolomucci A, Possenti R, Mahata SK, Fischer-Colbrie R, Loh YP, Salton SR. The extended granin family: structure, function, and biomedical implications. Endocr Rev. 2011;32(6):755-97.

35. Zollner S, Pritchard JK. Overcoming the winner's curse: estimating penetrance parameters from case-control data. Am J Hum Genet. 2007; 80(4):605-15.

36. Laitinen T, Rasanen M, Kaprio J, Koskenvuo M, Laitinen LA. Importance of genetic factors in adolescent asthma: a population-based twin-family study. Am J Respir Crit Care Med. 1998;157(4 Pt 1):1073-8.

37. McGeachie MJ, Stahl EA, Himes BE, Pendergrass SA, Lima JJ, Irvin CG, et al. Polygenic heritability estimates in pharmacogenetics: focus on asthma and related phenotypes. Pharmacogenet Genomics. 2013;23(6):324-8.

38. Lima-Costa MF, Rodrigues LC, Barreto ML, Gouveia M, Horta BL, Mambrini J, et al. Genomic ancestry and ethnoracial self-classification based on 5,871 community-dwelling Brazilians (The Epigen Initiative). Sci Rep. 2015;5:9812.

39. Barreto ML, Cunha SS, Alcantara-Neves N, Carvalho LP, Cruz AA, Stein RT, et al. Risk factors and immunological pathways for asthma and other allergic diseases in children: background and methodology of a longitudinal study in a large urban center in Northeastern Brazil (Salvador-SCAALA study). BMC Pulm Med. 2006:6:15.

40. Istituto Brasileiro de geografia e Estatistica - Sistema SIDRA [http://www. sidra.ibge.gov.br/bda/tabela/listabl.asp?z=cd\&o=4\&i=P\&c=3145]. Accessed 03 Oct 2014

41. Asher M, Keil U, Anderson H, Beasley R, Crane J, Martinez F, et al. International Study of Asthma and Allergies in Childhood (ISAAC): rationale and methods. Eur Respir J. 1995;8(3):483-91.

42. Thornton T, Tang H, Hoffmann TJ, Ochs-Balcom HM, Caan BJ, Risch N. Estimating kinship in admixed populations. Am J Hum Genet. 2012;91(1): $122-38$
43. Laurie CC, Doheny KF, Mirel DB, Pugh EW, Bierut LJ, Bhangale T, et al. Quality control and quality assurance in genotypic data for genome-wide association studies. Genet Epidemiol. 2010;34(6):591-602.

44. Pino-Yanes M, Thakur N, Gignoux CR, Galanter JM, Roth LA, Eng C, et al. Genetic ancestry influences asthma susceptibility and lung function among Latinos. J Allergy Clin Immunol. 2015;135(1):228-35.

45. Hancock DB, Romieu I, Shi M, Sienra-Monge JJ, Wu H, Chiu GY, et al. Genome-Wide Association Study Implicates Chromosome 9q21.31 as a Susceptibility Locus for Asthma in Mexican Children. PLoS Genet. 2009;5(8): e1000623.

46. Price AL, Patterson NJ, Plenge RM, Weinblatt ME, Shadick NA, Reich D. Principal components analysis corrects for stratification in genome-wide association studies. Nat Genet. 2006:38(8):904-9.

47. Magi R, Morris AP. GWAMA: software for genome-wide association metaanalysis. BMC Bioinformatics. 2010;11:288.

48. Howie BN, Donnelly P, Marchini J. A flexible and accurate genotype imputation method for the next generation of genome-wide association studies. PLoS Genet. 2009;5(6):e1000529.

49. Genomes Project C, Abecasis GR, Altshuler D, Auton A, Brooks LD, Durbin RM, et al. A map of human genome variation from population-scale sequencing. Nature. 2010;467(7319):1061-73.

50. Yang J, Benyamin B, McEvoy BP, Gordon S, Henders AK, Nyholt DR, et al. Common SNPs explain a large proportion of the heritability for human height. Nat Genet. 2010;42(7):565-9.

51. Lee PH, Perlis RH, Jung JY, Byrne EM, Rueckert E, Siburian R, et al. Multi-locus genome-wide association analysis supports the role of glutamatergic synaptic transmission in the etiology of major depressive disorder. Trans Psychiatry. 2012;2:e184

\section{Submit your next manuscript to BioMed Central and we will help you at every step:}

- We accept pre-submission inquiries

- Our selector tool helps you to find the most relevant journal

- We provide round the clock customer support

- Convenient online submission

- Thorough peer review

- Inclusion in PubMed and all major indexing services

- Maximum visibility for your research

Submit your manuscript at www biomedcentral.com/submit 